\title{
A doutrina da norma completa de Hans Kelsen
}

\section{The Doctrine of Hans Kelsen's Complete Standard}

JOSÉ JOAQUIM MONTEIRO RAMOS*

jose.j.ramos@mpublico.org.pt

GALILEU - REVISTA DE DIREITO E ECONOMIA - e-ISSN 2184-1845

Volume XXI $\cdot 1^{\text {st }}$ July Julho - 31 $1^{\text {st }}$ December Dezembro $2020 \cdot$ pp. 7-24

DOI: https://doi.org/10.26619/2184-1845.XXI.2.1

Submitted on September $22^{\text {th }}, 2020 \cdot$ Accepted on November $10^{\text {th }}, 2020$

Submetido em 22 de setembro 2020 . Aceite a 10 de novembro, 2020

SUMÁRIO Introdução 1. Características do Sistema Normativo 1.1. A Teoria da Estrutura Escalonada do Direito 1.2. O Sistema Jurídico Como Ordem Normativa Dotada de Coação 2. Norma Completa 3. Norma Completa e Nomoestática/Nomodinâmica Síntese e considerações finais.

PALAVRAS-CHAVE normatividade, estrutura escalonada, coacção, norma completa.

SUMARRY Introduction 1. Characteristics of the Normative System 1.1. The Theory of Staggered Structure of Law 1.2. The Legal System as a Normative Order with Coercion 2. Complete Standard 3. Complete Standard and staticrule/dinamicrule Summary and final considerations.

KEYWORDS normativity, staggered structure, coercion, complete norm.

\footnotetext{
* Procurador da República. Mestre em Direito. Doutorando pela Universidade Autónoma de Lisboa. Professor con-
} vidado da Universidade Autónoma de Lisboa. 


\section{Introdução}

Logo no início da sua mais conhecida e emblemática obra Hans Kelsen deixa bem esclarecido o seu desiderato científico o qual motivou a larga maioria dos seus estudos ${ }^{1}$ e que o mesmo identifica como a indagação do objecto do Direito, na sua dimensão de jurisprudência analítica, em termos tais que procurará responder apenas à questão de "o que é e como é o direito" ${ }^{2}$. Essa finalidade importa, para Kelsen, a assunção de um princípio metodológico de pureza na construção dogmático-jurídica impondo o afastamento de tudo o que se possa confundir com o objecto do Direito, mas que summo rigore lhe é estranho, como são a sociologia, a psicologia e as valorações decorrentes da ética e da teoria política ${ }^{3}$.

Os actos humanos não são de per si fenómenos jurídicos uma vez que só assumem tal relevância se e quando uma norma jurídica o determinar, razão pela qual entre o acto concreto praticado por determinado indivíduo e o seu relevo jurídico, está a norma de Direito que lhe dá significação jurídica. A norma opera, pois, como meio interpretativo de actos humanos conferindo-lhes a qualidade de jurídico (ou antijurídico) ${ }^{4}$. A norma que atribui ao acto humano um sentido jurídico é, ela própria, gerada por outro acto humano que recebe a sua significação jurídica de outra norma, o que importa a verificação que a juridicidade não é circunstância perceptível pelos sentidos, mas que apenas se alcança por operações de matriz intelectual concretizáveis pela concatenação entre o facto e a previsão da norma jurídica eventualmente aplicável ${ }^{5}$ (juízo de subsunção).

Do exposto decorre que o objecto da ciência do Direito não são factos, mas normas, as quais são integrantes e constituintes de um sistema ${ }^{6}$ o qual especificam como normológico.

\footnotetext{
1 Apesar de Hans Kelsen ficar conhecido como o autor da Teoria Pura do Direito a qual se pode sintetizar em quatro teorias ou doutrinas (normatividade ideal do Direito, norma fundamental, estrutura escalonada do Direito e a norma completa), a sua obra é muito mais ampla e profunda, v. g., a teoria monista com primado do direito internacional e a questão do controlo/fiscalização da constitucionalidade das leis, que levantou acesso debate com Carl Schmitt. Sobre o debate entre estes dois "gigantes do Sec. XX", CUnHA, PAUlo FerReIRA DA- Repensar o Direito - Um Manual de Filosofia Jurídica. Lisboa: INCM - 2013.

2 Kelsen, HAns - Teoria Pura do Direito: 2. edição (1960). Tradução da 7. edição alemã de João Baptista Machado. , Coimbra: Almedina - 2008, p. 1. Do mesmo modo, já em 1911, na sua tese de habilitação, Hauptprobleme der Staasrechtslehre, entwickelt aus der Lehre vom Rechtssatze, Tübigen - 1911, Hans Kelsen afirmara que o seu objectivo se centrava na purificação epistemológica do direito, mormente no seu método.

3 Kelsen, Hans - Teoria Pura do Direito ..., p. 1.

4 Kelsen, Hans - Teoria Pura do Direito ..., p. 2.

5 Kelsen, Hans - Teoria Pura do Direito ..., p. 2.

6 Claus Wilhelm Canaris critica a concepção pura do sistema normativo em Kelsen, bem como todos os sistemas assim entendidos, por entender que se referem a qualquer ordem jurídica considerável em abstracto, o que é irreal uma vez que a unidade valorativa é sempre material e só é susceptível de realização numa dada ordem jurídica histórica determinada, CANARIs, CLAUS WILHELM - Pensamento Sistemático e Conceito de Sistema na Ciência do Direito. 2. ${ }^{a}$ Edição. Tradução de António Menezes Cordeiro. Lisboa: Fundação Calouste Gulbenkian, 1996, p. 27. O próprio Kelsen, em carta datada de 3 de Agosto de 1933 e dirigida a Renato Treves, assume que a Teoria Pura do Direito toma como ponto de partida o sistema jurídico (epístola transcrita por Stanley Paulson e Bonnie Paulson - Normativity and Norms, Critical Perspectives on Kelsen Themes, Oxford,1998, pp. 169 a 175).
} 
O Direito tem, pois, a característica da ideal normatividade e, como fenómeno exclusivonormativo $^{7}$, está limitado pela lei de Hume ${ }^{8}$, importando que ser e dever ser são categorias distintas e independentes entre si, estando separados, segundo o nosso autor, por um "abismo intransponível" . A norma é o único critério de valoração jurídica do facto, porquanto os postulados de factos são insuscetíveis de gerar juízos jurídicos. Só a norma dá valor jurídico ao facto ${ }^{10}$.

A assunção que a norma integrada num sistema jurídico constitui o objecto do Direito tem como substracto epistemológico a filosofia Kantiana do apriorismo das formas transcendentais do conhecimento, na visão da escola de Marburgo, com destaque para os estudos de Herman Cohen ${ }^{11}$. O dever ser kelseniano assume natureza lógico-transcendental na medida em que representa uma categoria pura, não metafísica, à qual se chega apenas por análise lógica de pensamento ${ }^{12}$.

Assim definido na sua plenitude o objecto do Direito como ciência, fica afastada a possibilidade de confusão conceptual entre as ciências da Sociologia e do Direito ${ }^{13}$, sendo que o objecto daquela ciência são factos e o objecto do Direito são normas. Com esta refundação da jurisprudência como actividade científica Hans Kelsen pode afastar a critica da acientificidade do Direito por o mesmo não estar dotado de óbjecto, método ou técnica, critica que, em especial, foi formulada por Eugen Ehrlich ${ }^{14}$.

7 Matos, Anditas Soares de Moura Costa - «Kelsen e a Violência: Uma Leitura Crítica das "Limitações" da Teoria Pura do Direito»: In: Júlio Aguiar de Oliveira e de Alexandre Travessoni Gomes Trivisonno (Coord.). Hans Kelsen - Teoria Jurídica e Política. São Paulo: Forense Universitária,2013, p. 257.

8 Kelsen, HANS - Teoria Geral das Normas. Tradução de José Florentino Duarte. Porto Alegre: Sérgio António Fabris Editor, 1986, p. 108. Sobre a aceitação da Lei de Hume por Hans Kelsen ver, GreEN, MichAel SteVEN - «Hans Kelsen and the Logic of Legal Sistems». Consultado a 10/10/2019 em http://scholarship.law.wm.edu/cgi/viewcontent. cgi?article, p. 390.

9 Hume apud LAMEgo, José - «O conceito de Direito como forma lógica da "experiência" jurídica: a filosofia do Direito do neo-kantismo de Marburgo». In: Caminhos da Filosofia do Direito Kantiana - I volume de Kant ao NeoKantismo. Lisboa: AAFDL, 2014, p. 93.

10 Nino, CARlos SANTIAGo - Introducción al Análisis del Derecho. 2. ${ }^{a}$ edição, 12. ${ }^{a}$ reimpressão. Buenos Aires: Editorial Astrea,2003, p. 122.

11 É elucidativo o texto de Kelsen, na já referida epistola a Renato Treves (nota 6), ao afirmar que "É totalmente correcto que a base filosófica da Teoria Pura do Direito é filosifia Kantiana, em especial a filosofia Kantiana na interpretação que lhe foi dada por Cohen" (tradução livre).

A filosofia epistemológica Kantiana foi assumida na Alemanha por duas escolas, a de Marburgo e a de Baden. A escola de Marburgo, com especial destaque para Herman Cohen (1842-1918) reflectiu fundamentalmente sobre as condições de possibilidade da experiência, numa refundação da epistemologia kantiana (apriorismo lógicotranscendental das categorias possibilitadoras do conhecimento) e a escola de Baden aprofundou o estudo dos apriorismos transcendentais da cultura e do mundo.

12 LAMEgo, JosÉ. - «A argumentação transcendental em Kelsen». In: Caminhos da Filosofia do Direito Kantiana - I volume de Kant ao Neo-Kantismo. Lisboa: AAFDL,2014, p. 114.

13 Assim, LAREnZ, KARL - Metodologia da Ciência do Direito. 3. Edição. Tradução de José Lamego, Lisboa: Fundação Calouste Gulbenkian, 1997, p. 93.

14 Ehrlich, Eugen - Fundamentos da Sociologia do Direito. Tradução de René Ernani Gertz. Brasília: Editora Universidade de Brasília, afasta a natureza científica do Direito remetendo-o a uma função meramente técnica, postulando que a verdadeira ciência do Direito era a Sociologia do Direito. 
O iter que, de forma necessária e sintética, percorremos afastou do objecto do direito as ideologias (inerentes ao direito natural) ${ }^{15}$ e os factos (matéria para o labor da Sociologia do Direito), definindo-se o objecto da ciência do Direito como as normas que integram sistemas jurídicos, assumindo-se a jurisprudência como ciência e a única ciência do Direito ${ }^{16}$.

\section{Características do Sistema Normativo}

O sistema jurídico é, para Hans Helsen, caracterizado pela relação vertical e escalonada das normas que o constituem ${ }^{17}$ e pela sua capacidade de coacção, particularidade esta última que o diferencia das demais ordens normativas sociais, como a moral e a religião ${ }^{18}$.

\subsection{A Teoria da Estrutura Escalonada do Direito}

A Teoria da Estrutura Escalonada do Direito (Stufenbaulehre) é construção dogmática de Adolf Julius Merkel ${ }^{19}$ e foi por Kelsen recepcionada no âmbito da Teoria Pura do Direito ${ }^{20}$. A assunção que a norma jurídica só é válida se receber a sua legitimidade para integrar o sistema normativo se uma outra norma - necessariamente de escalão superior - assim o determinar ${ }^{21}$ importa a existência de uma cadeia vertical e sucessiva de normas de atribuição de competência por forma a que todas as normas produzam os efeitos jurídicos pre-

15 Sem embargo da obra de Hans Kelsen se traduzir no estudo das formas do Direito e de negar a existência de qualquer referência axiológica inerente aos sistemas normativos uma vez que tal é questão de opção política por via do exercido do poder legislativo, não deixou o mesmo de realizar estudos na área da Justiça como valor humano. Sobre esses estudos ver LAMEgo, José - «A doutrina Kelseniana da Justiça». In: A Teoria Pura do Direito de Kelsen. Lisboa: AAFDL, 2019, pp. 165 a 176, e PIres, Alex SANDER XAVIER - Justiça na Perpectiva Kelseniana. Rio de Janeiro: Freitas Bastos Editora, 2013.

16 Bobbio, Norberto - Direito e Poder. Tradução de Nilson Moulin. São Paulo: Unesp, 2008, p. 24.

17 Kelsen, Hans - Teoria Pura do Direito ..., p. 250.

18 Kelsen, Hans - Teoria Pura do Direito ..., p. 41, e Kelsen, Hans - Teoria Geral do Direito e do Estado, tradução de Luís

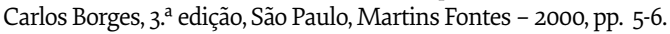

19 Sobre a autoria, génese e evolução da Teoria da Estrutura Escalonada do Direito e da sua recepção por parte de Hans Kelsen, ver BorowsKi, MARTIN - «A Doutrina da Estrutura Escalonada do Direito de Adolf Julius Merkl e a sua Recepção em Kelsen». In: Júlio Aguiar de Oliveira e de Alexandre Travessoni Gomes Trivisonno (Coord.). Hans Kelsen - Teoria Jurídica e Política. coordenação de São Paulo: Forense Universitária, 2013, pp. 129 a 183. O autor defende que, injustamente, Adolf Julius Merkel foi colocado na sombra de Hans Kelsen quando é certo que os seus trabalhos têm uma "qualidade impressionante e que entre os teóricos esquecidos do direito poucos há com a sua qualidade".

O próprio Hans Kelsen, logo em 1923, no prefácio de Hauptprobleme der Staatsrechtslehre, reconhecia a importância de Adolf Julius Merkel para a assunção de uma visão nomodinâmica na Teoria Pura do Direito.

20 Paulson, StAnley - «Reflexões Sobre a Periodização da Teoria do Direito de Hans Kelsen». In: de Júlio Aguiar de Oliveira e de Alexandre Travessoni Gomes Trivisonno (Coord.). Hans Kelsen - Teoria Jurídica e Política. São Paulo: Forense Universitária, 2013, pp. 21 a 24.

21 Kelsen, Hans- Teoria Pura do Direito ..., p. 2. 
tendidos, sendo a validade de cada norma aferida em razão da norma de escalão superior que a autoriza ${ }^{22}$.

O sistema normativo assim entendido responde à questão de saber quais as normas válidas, mas, de forma concomitante, cria outro problema: o de saber onde terminam as normas de atribuição de competência, i. e., invertendo o sentido lógico que temos vindo a percorrer, qual a primeira norma que permite o início da cadeia de permissões legislativas.

A Teoria da Estrutura Escalonada do Direito pode ser graficamente representada por uma pirâmide cujo vértice superior corresponde à Constituição, o escalão intermédio respeita às normas superiores emanadas pelos órgãos estaduais com competência legislativa e o escalão inferior acomoda as normas inferiores ou normas individuais que correspondem a decisões/deliberações judiciais ou administrativas, bem como aos actos dos sujeitos de direito que criam auto-vinculações. Se a Constituição importa a validade das normas dos dois níveis hierarquicamente inferiores e ela própria é revista nos termos constitucionalmente previstos, a questão é apenas a de saber qual a força jurídica (validade) da primeira Constituição historicamente considerada ${ }^{23}$ e na qual as posteriores Constituições recolhem a sua força vinculativa. O pensamento tributário da lógica deôntica não pode deixar de concluir pela existência de uma norma pressuposta ${ }^{24}$ - e não posta, tal como todas as demais normas - que corresponde à "norma fundamental"25 do sistema e que permite não

22 Herbert Hart em face da questão do fundamento da validade normativa, defende a existência da rule of recognition segundo a qual são válidas as normas que forem aceites pela praxis social de cada comunidade humana concretamente determinada no seu momento histórico. A rule of recognition é uma questão de matéria de facto e apenas é verificável pela análise das práticas sociais, uma vez que não é formulada de forma explícita, HART, Herbert - O Conceito de Direito. 6. ${ }^{a}$ Edição. Tradução de Armindo Ribeiro Mendes. Lisboa: Fundação Calouste Gulbenkian - 2011, pp. 113 e ss.

Sobre a regra do reconhecimento e a sua interacção dogmática com a Teoria Pura do Direito ver, SPAAK, TORBEN- «Kelsen and Hart on the Normativity of Law». Consultado a 24/10/2019, disponível http://www. scandinavianlaw.se/pdf/48-24.pdf, p. 408 e ss., e Dimoulis, Dimitri E LunARDI, SORAYA- «A Validade do Direito na Pespectiva Juspositivista. Reflexões em Torno de Hans Kelsen». In: Júlio Aguiar de Oliveira e de Alexandre Travessoni Gomes Trivisonno (Coord.). Hans Kelsen - Teoria Jurídica e Política. São Paulo: Forense Universitária, 2013, pp. 223 e ss.

23 Como o próprio Hans Kelsen admite este caminho histórico-constitucional de validações sucessivas pode ser quebrado pelas vicissitudes próprias de todas as normas, mormente por via revolucionária (cfr. Teoria Pura do Direito ..., pp. 223, 234, 244 e 304).

Com o mesmo fundamento, Matos, AnditAs SoARes de Moura Costa - «Kelsen e a Violência: Uma Leitura Crítica das "Limitações" da Teoria Pura do Direito». In: Hans Kelsen - Teoria Jurídica e Política..., p. 255, afirma que "o grande mérito da Teoria Pura do Direito consiste em ter revelado, mediante instrumento filosófico-jurídico, o carácter originalmente violento do direito".

24 Também Walter JellineK, já em 1913, na obra Gesetz, Gesetzesanwendung und ZweckmäBigkeitserwagung, tinha defendido a necessidade conceptual de uma norma de encerramento do sistema, à qual não correspondia qualquer vontade humana.

25 Para LAmego, JosÉ - «A função epistemológica e a função sistémica da norma fundamental». In: Caminhos da Filosofia do Direito Kantiana - I Volume - de Kant ao Neo-Kantismo..., p. 161: a norma fundamental é a doutrina mais emblemática da Teoria Pura do Direito. 
só o seu conhecimento científico, como também a fundamentação da cadeia de sucessivas autorizações ${ }^{26}$ reveladas pelo sistema jurídico ${ }^{27}$.

Tal norma assim pressuposta colhe o seu fundamento jurídico-filosófico na pressuposições lógico-transcendentais de Kant, na linha da escola de Magburgo e de Hernamn Cohen, uma vez que, não sendo empiricamente demonstrável a sua existência, é uma decorrência necessária da verificação de um objecto epistemológico (o sistema jurídico e a sua normatividade ideal) ${ }^{28}$, razão pela qual a norma fundamental não é mero resultado de um qualquer poder factual e arbitrário, mas sim da razão científica e, por essa via, demonstrável por método válido.

Hans Kelsen descreveu o teor da grundnorm ${ }^{29}$ como "devem ser postos actos de coerção sob os pressupostos e pela forma que estatuem a primeira Constituição histórica e as normas estabelecidas em conformidade com ela (Em forma abreviada: «devemos conduzir-nos como a Constituição prescreve»)"30. A ordem jurídica é, pois, um sistema composto por normas numa relação de hierarquia em que a validade das normas se afere em razão da norma superior que legitima a sua produção, todas colhendo validade do mesmo fundamento (a norma fundamental); assim "Uma norma singular é uma norma jurídica enquanto pertence a uma determinada ordem jurídica, e pertence a uma determinada ordem jurídica quando a sua validade se funda na norma fundamental dessa ordem"31.

26 Green, Michael SteVen - Hans Kelsen and the Logic of Legal Sistems..., p. 388.

27 Sobre a natureza e as funções da norma fundamental no âmbito da estrutura conceptual da Teoria Pura do Direito, designadamente a existência das duas perpectivas com que Hans Kelsen teorizou a grundnorm, ver RAMOS, José JoAquim Monteiro - «A Dupla Perspectiva da Norma Fundamental em Hans Kelsen». In: Politeia - Revista do Instituto Superior de Ciências Policiais e Segurança Interna. Lisboa, ano X-XI-XII, 2013, 2014, 2015, volume 1 - studia varia, pp. 213 a 233.

28 LAMEGo, JosÉ - «A argumentação transcendental em Kelsen». In: Caminhos da Filosofia do Direito Kantiana - I Volume - de Kant ao Neo-Kantismo..., p. 119.

29 ROSS, ALf - Direito e Justiça. Tradução de Edson Bini. São Paulo: Edipro, 200o, pp. 92 a 97, critica a Teoria da Norma Fundamental com o argumento que a mesma transforma Hans Kelsen num "quasi positivista" na medida em que a assunção da existência de uma entidade normativa não positiva, como é o caso da norma fundamental, não tem lugar numa teoria do direito positivo.

Do mesmo modo, Воввіо, Norberto - Direito e Poder..., p. 166, argui contra a Teoria da Norma Fundamental por a mesma consubstanciar uma derivação da fundamentação de direito para a matéria de facto. Também Mario Losano e Renato Treves, criticam a norma fundamental considerando-a um retorno à sociologia, em desconsideração da Lei de Hume, por a norma fundamental apenas ser possível em razão de operações de matriz sociológica. Mario Losano e Renato Treves apud MATos, ANDitAs SoARES DE Moura CostA - «Kelsen e a Violência: Uma Leitura Crítica das “Limitações" da Teoria Pura do Direito». In Hans Kelsen - Teoria Jurídica e Política..., p. 261.

30 Kelsen, Hans - Teoria Pura do Direito ..., p. 223.

31 Kelsen, Hans - Teoria Pura do Direito ..., p. 35. 


\subsection{O Sistema Jurídico como Ordem Normativa Dotada de Coacção}

Na estrutura do pensamento de Hans Kelsen o Direito é uma ordem social normativa que se distingue das demais ordens sociais normativas (como a moral) pela sua característica da coactividade ${ }^{32}$, uma vez que os seus comandos podem ser aplicados, se necessário for, pelo uso da força ${ }^{33}$. A definiç̧ão Kelseniana de Direito é realizada em razão de três fundamentais particularidades, a saber: o Direito é uma ordem social, normativa, que corresponde a uma técnica de motivação indirecta de condutas por cominação de sanções coercitivas para as condutas que quer desencorajar ${ }^{34}$.

A especificidade do Direito não opera em razão da mera previsão de sanções uma vez que também outras ordens normativas sociais comportam no seu sistema a existência de sanções, porém, apenas o Direito tem a possibilidade de aplicar as sanções pela via da coerção.

Na construção dogmático-conceptual elaborada pelo nosso autor, esta característica da coercibilidade do Direito é essencial na medida em que permite a distinção entre o Direito e as demais ordens normativas sociais, assim concretizando uma das suas maos importantes aspirações epistemológicas, a saber: a definição da norma jurídica como objecto da jurisprudência, permitindo a afirmação da ciência do Direto como verdadeira e própria ciência que não se confunde com a sociologia do Direito, ciência à qual fica reserva o estudo do factos.

A ideia da normatividade do Direito está, pois, associada à prescrição de sanções e à possibilidade da sua imposição coactiva ${ }^{35}$, de tal forma que "a fórmula com a qual traduzimos a norma fundamental de uma ordem jurídica estadual significa: a coacção de um indivíduo por outro deve ser praticada pela forma e sob os pressupostos fixados pela primeira Constituição histórica" ${ }^{36}$. O sistema jurídico colhe a ontológica característica da

32 Afonso, Elza Maria miranda - "Passos da Teoria de Kelsen Rumo à Construção da Teoria do Direito». In: Júlio Aguiar de Oliveira e de Alexandre Travessoni Gomes Trivisonno (Coord.). Hans Kelsen - Teoria Jurídica e Política São Paulo, Forense Universitária - 2013, p. 57.

33 Kelsen, Hans - Teoria Pura do Direito ..., p. 41 e Teoria Geral do Direito e do Estado..., pp. 21 a 30.

34 LAMEgo, José - «O Direito como Técnica Social de Motivação Indirecta de Condutas» In: A Teoria Pura do Direito de Kelsen..., p. 69.

35 Ross, Alf - Direito e Justiça..., pp. 77 e 78, expressamente manifesta o seu desacordo com Hans Kelsen afirmando que a aplicação das normas é assegurada pela força, mas as normas não são necessariamente coactivas porquanto tal asserção equivaleria à desconsideração das normas atribuidoras de competência e das normas que considera secundárias e que permitem a aplicação das normas reguladoras das condutas (estas que denomina de primárias).

36 Kelsen, Hans - Teoria Pura do Direito ..., p. 56. 
coactividade ${ }^{37}$ desde logo na norma fundamental ${ }^{38}$ que legitima toda a estrutura normativa a jusante, razão pela qual apenas existe dever jurídico quando a conduta que lhe é oposta seja pressuposto de um acto coercitivo ${ }^{39}$ ou, numa asserção materialmente semelhante, toda a obrigação, para ser qualificada como jurídica e não como meramente moral - em caso de ilicitude no seu cumprimento - tem de estar associada a uma sanção que pode ser imposta pela utilização da força ${ }^{40}$.

O Direito tende a regular os isos que comportam a utilização da força uma vez que querendo evitar a utilização da força entre os membros da comunidade realiza tal desiderato pela utilização da própria força. A esta contradição ${ }^{41}$ responde Hans Kelsen que a mesma é uma antinomia meramente aparente porquanto o Direito é a organização da força que procura promover a paz, razão pela qual força e Direito não devem ser considerados antagônicos, justamente porque "na regra jurídica, o emprego da força surge como delito, i.e., a condição para a sanção, ou como sanção, i.e., a reacção da comunidade jurídica contra o delito"42. A finalidade da coercção justifica a utilização da força para a imposição de sanções jurídicas desde que as normas tenham sido produzidas dentro da estrutura escalonada do Direito e segundo o modelo previsto na respectiva ordem jurídica.

Contudo, Hans Kelsen não desconhece que a ordem jurídica comporta normas que, de per si, não preveem a possibilidade de sanções nem, em consequência, assumem a característica da coercitividade, como são v.g. as normas atribuidoras de competência e as normas que consubstanciam a previsão de cânones hermenêuticos.

37 Engisch, KARL - Introdução ao Pensamento Jurídico. 7. edição. Tradução de João Baptista Machado. Lisboa: Fundação Calouste Gulbenkian, 1996, p. 34, estribando-se no postulado Kelseniano da coercitividade da ordem jurídica e assumindo que todas as normas são criadoras de direitos e deveres, afirma como corolário que os direitos e deveres dos particulares são correlativos de direitos e deveres das entidades estaduais uma vez que só assim a coercitividade para garantia de direitos e deveres é possível.

38 HART, HeRbert - O Conceito de Direito... pp. 111 e ss, entende que o sistema jurídico está dotado de uma dupla via para concretizar a obediência às normas: por um lado concorda com Hans Kelsen em relação à coercibilidade intrínseca à ordem jurídica e, por outro lado, devido ao que entende por rule of recognition que tem na estrutura do sistema jurídico por si construído função semelhante à grundnorm (cfr. nota 22), considera a existência de um "fenómeno social complexo" uma vez que a comunidade entende e aceita as normas o que gera uma generalizada obediência.

39 Kelsen, Hans- Teoria Pura do Direito ..., p. 56.

40 Bobbio, Norberto - Teoria do Ordenamento Jurídico. 6. edição. Tradução de Maria Celeste Cordeiro Leite dos Santos, Brasília: UnB, 1982, pp. 68 a 70, critica esta posição de Hans Kelsen por considerar que o mesmo confunde a força do instrumento jurídico da regulação com o seu objecto, as normas estão dotadas de coercibilidade, mas não são coercibilidade. Considera Norberto Bobbio que "o objecto de todo o legislador não é organizar a força, mas organizar a sociedade mediante a força".

41 Silva, Ivan de Oliveira - Filosofia do Direito. São Paulo: Editora Atlas, 2010, p. 71.

42 Kelsen, Hans - Teoria Geral do Direito e do Estado..., p. 31. 


\section{A Norma Completa}

A existência de normas que em si mesmas consideradas não prescrevem sanções para a sua violação não obsta à definição do Direito como ordem normativa social dotada de coerção na medida em que o ordenamento jurídico é composto de uma "estatuição geral do acto de coacção" ao qual se chega pela hermenêutica jurídica ${ }^{43}$, sendo que a cocção não necessita de estar expressamente prevista na norma mas apenas de estar autorizada ou de ser permitida, sem embargo do acto coactivo estatuído de modo geral corresponder a uma prescrição expressa.

O sistema comporta a possibilidade de, por acto legislativo e seguindo um procedimento conforme à norma fundamental, se aprovar norma que determine certa conduta e não prever sanção nem, consequentemente, a possibilidade da coacção, como é o caso da obrigação natural ${ }^{44}$, porém tal norma porque não respeita o sentido objectivo de coercibilidade da norma fundamental não pode ser tida como norma jurídica.

Uma análise mais aprofundada do sistema jurídico revela a existência de normas não autónomas as quais Hans Kelsen conceptualizou como as que fixam os pressupostos que legitimam a aplicação do acto coercivo.

São normas jurídicas não autónomas ${ }^{45}$ todas as que não prescrevem sanções coercitivas, as quais se podem cindir em cinco diferentes categorias; a) as normas secundárias (que prescrevem condutas e que, necessariamente, estão conexas com normas que estatuem a sanção coercitiva para o caso de não observância), b) as normas que facultam condutas, c) as nomas revogatórias, d) as normas de atribuição de competência e e) as normas que regulam a actividade jurídico- hermenêutica ${ }^{46}$.

As normas autónomas são, pois, as que estatuem o acto geral de coercção, uma vez verificados os pressupostos de que tal acto depende e que constituem o conteúdo das normas secundárias.

A construção da proposição normativa, no entendimento de Hans Kelsen gera-se pela relação entre a norma autónoma e as normas não autónomas que constituem os pressupostos de aplicação do acto coercivo naquela estatuído. Atentemos no exemplo que o próprio Kelsen escreveu a respeito do ilícito de furto "Se os indivíduos competentes para legislar estabelecerem uma norma geral por força da qual quem comete furto deve ser

43 Kelsen, Hans - Teoria Pura do Direito ..., p. 57.

44 Que, no ordenamento jurídico português, encontra o seu regime nos artigos $402 .^{\circ}$ e $404 .^{\circ}$ do Código Civil.

45 Para uma mais aprofundada análise da noção de norma não autónoma, ver D’ALMEIDA, Luís DUARTE - «In Canonical Form: Kelsen's Doctrine of the Complete Legal Norm».In: Luís Duarte D’Almeida, J. Gardner e L. Green (Coord.). Kelsen Revisited. New Essays on the Pure Theory of Law. de. Edimburgo: Hart Publishing, 2013, pp. 266 e ss.

46 Kelsen, Hans - Teoria Pura do Direito ..., pp. 61 a 65. 
punido de certa maneira, e se o tribunal competente segundo o ordenamento processual penal verificou, de conformidade com um procedimento fixado pelo mesmo ordenamento processual, que determinado indivíduo cometeu um furto, e este mesmo tribunal aplicou a pena legalmente fixada, então deve um certo órgão executar essa pena"47.

A proposição jurídica descritiva assim entendida corresponde à plenitude de todas as normas - orgânicas, processuais e substantivas, independentemente do lugar que ocupam na estrutura escalonada do sistema jurídico em que concretamente se encontram - que estão funcionalmente organizadas em razão da aplicação do Direito a cada caso concreto. Na verdade, cada norma (autónoma ou não autónoma) corresponde a um mero fragmento ${ }^{48}$ da norma completa que summo rigore é a proposição jurídica reveladora do dever $\operatorname{ser}^{49}$.

A doutrina da norma completa adequa e harmoniza, numa relação bidireccional, as teses da estrutura escalonada do Direito e a sua caracterização como coercivo porquanto compatibiliza a relação normativa hierárquica, conjugando num encadeamento funcional normas de diversos escalões da estrutura, com a característica coerciva da grundnorm que transmite às normas individuais integrantes do escalão mais baixo da ordem jurídica. Destarte, fica assegurada a harmonia intrassistémica da ordem jurídica que assume a coercibilidade como característica comum a todos os seus escalões ${ }^{50}$.

As diversas normas autónomas e não autónomas (todo o material dado nas normas de uma ordem jurídica) estão envolvidas num processo epistemológico tendente à fixação da concreta norma individual que revelará o dever ser casuístico, cujo resultado depende de critérios epistemológicos ${ }^{51}$. A proposição jurídica é o resultado da actividade conjunta do

47 Kelsen, Hans- Teoria Pura do Direito ..., p. 63.

D'AlmeidA, Luís DuARTE - «In Canonical Form: Kelsen's Doctrine of the Complete Legal Norm». In: Kelsen Revisited. New Essays on the Pure Theory of Law..., pp. 263 e ss., realiza, sob a perspectiva norma autónoma/noma não autónoma, uma análise ao exemplo do furto.

À luz desta descrição, entende-se a posição de LAMEGO, JosÉ - «O Direito como Técnica Social de Motivação Indirecta de Condutas». In: A Teoria Pura do Direito de Kelsen..., pp. 69 e 70, segundo o qual a caracterização do Direito como ordem de coerção importa a simultânea verificação e duas teses, que são consistentemente lógicas com a estrutura do pensamento Kelseniano, mas contra-intuitivas, a norma completa e a afirmação que os destinatários das normas jurídicas hipotéticas individuais são os indivíduos a quem está atribuído o poder de resolver o caso concreto (juízes e funcionários).

48 Lamego, José - «O Direito como Técnica Social de Motivação Indirecta de Condutas». In: A Teoria Pura do Direito de Kelsen..., p. 74.

49 Para Hans Kelsen a proposição jurídica é conceito diverso de norma jurídica, uma vez que a proposição corresponde a um enunciado que descreve uma ou várias normas jurídicas. Assim Nino, CARLOS SANTIAGOIntroducción al Análisis del Derecho..., p. 87.

50 Entende-se, pois, que o próprio Hans Kelsen na já referida carta a Renato Treves (cfr. notas 6 e 11) se refira à Doutrina da Norma Completa como o cerne da Teoria Pura do Direto.

51 Kelsen, Hans - Teoria Pura do Direito ..., p. 65.

Assim, Matos, Anditas Soares de Moura Costa - «A Norma Fundamental de Hans Kelsen Como Postulado Científico». In: Revista da Faculdade de Direito UFMG. Belo Horizonte, n. ${ }^{\circ}$ 58, janeiro/junho 2011, p. 48. 
legislador e do aplicador do Direto ${ }^{52}$. A norma completa ${ }^{53}$ traduz, pois, pela concatenação entre normas autónomas e não autónomas e operada pela reconstrução que o aplicador do Direito realiza, o juízo hipotético da relação de imputação jurídica (se A é, B deve ser $\left.{ }^{54}\right)^{55}$.

\section{Norma Completa e Nomoestática/Nomodinâmica}

É frequentemente apontada a Hans Kelsen a dificuldade ${ }^{56}$ que a Doutrina da Norma Completa tem para se compatibilizar, simultaneamente, com as visões nomoestática e nomodinâmica do Direito, uma vez que a mesma teoria foi pensada num quadro de investigação científica que procurava identificar o objecto do Direito e diferenciá-lo de outras ordens normativas sociais, bem como restringir as normas jurídicas a uma forma lógica comum reveladora do dever ser. A conjugação destas preocupações epistemológicas não podia deixar de ser tributária de uma ideia estática de ordem jurídica centrada no apuramento das condições de aplicação das sanções coercitivas revelando a existência de normas autónomas e não autónomas e na sua união finalisticamente orientada para a casuística aplicação das mesmas sanções.

É neste ambiente científico que surge a Doutrina da Norma Completa.

A recepção por Hans Kelsen da Teoria da Estrutura Escalonada do Direito no seu edifício conceptual ${ }^{57}$, veio dar enfâse às normas de atribuição de competência, iniciando uma viragem nos estudos Kelsenianos em direcção a uma visão dinâmica da ordem jurídica ${ }^{58}$. Esse percurso foi acentuado com a publicação da $1^{\mathrm{a}}$ edição da Teoria Pura do Direito (em 1934) na qual resulta a dificuldade da bipartição entre normas autónomas e não autónomas.

52 Postulado que está de harmonia com a teoria kelseniana da interpretação jurídica, uma vez que vez a interpretação jurídica é "uma operação mental que acompanha o processo de aplicação do Direito no seu progredir de um escalão superior para um escalão inferior" [Teoria Pura do Direito ..., p. 379]. O texto sobre interpretação jurídica que Hans Kelsen publicou, nesta 2. ${ }^{a}$ edição da Teoria Pura do Direito, é praticamente igual (mudou a expressão "produção do Direito" para "aplicação do Direito") ao texto publicado na 1. a edição da mesma obra (1934) e no artigo de 1934 Zur Theorie der Interpretation.

53 Surge pela primeira vez na tese de habilitação de Hans Kelsen - Hauptprobleme der Staasrechtslehre, entwickelt aus der Lehre vom Rechtssatze, Tübigen, 1911.

54 HaRtney, Michael- «Introduction: The Final Form of The Pure Theory of Law». In: General Theory of Norms. Oxford: Oxford Scholarship, 1991, p. XXii.

55 Máynes, Eduardo Garcia-, Filosofia del Derecho. 10. edição. Cidade do México: Porrua, 1998, p. 51 e ss., defende que este é, também o fundamento da distinção entre o Direito e outras ordens normativas sociais, como a religião, a moral e os usos sociais.

56 Assim, Lamego, José-, «O Direito como Técnica Social de Motivação Indirecta de Condutas». In: A Teoria Pura do Direito de Kelsen..., p. 72.

57 O que sucedeu nos anos 20 do século passado, Borowski, MARTiN-«A Doutrina da Estrutura Escalonada do Direito de Adolf Julius Merkl e a sua Recepção em Kelsen». In: Hans Kelsen - Teoria Jurídica e Política..., p. 176.

58 LAMEgo, José - «O método transcendental da filosofia do Direito: a polémica entre Kelsen e Sandre». In: Caminhos da Filosofia do Direito Kantiana - I volume ..., p. 141. 
Com o exílio nos Estados Unidos, Hans Kelsen foi confrontado com uma nova realidade gnosiológica e mostrou-se sensível aos argumentos da filosofia da linguagem e do realismo epistemológico59, o que introduziu dificuldades intrasistémicas na Teoria Pura do Direito. A publicação, em 1945, da Teoria Geral do Direito e do Estado, reflete estas novas circunstâncias e Hans Kelsen assume uma visão nomodinância da ordem jurídica ${ }^{60}$, sem, contudo, deixar de a tentar harmonizar com a nomoestática. Na segunda edição da Teoria Pura do Direito o autor aprofunda o estudo da dimensão dinâmica do sistema jurídico procurando manter a sua compatibilização com a nomoestática.

A nomoestática consiste no segmento da jurisprudência analítica que estuda os elementos essenciais integrantes do sistema jurídico e das suas condições para qualquer ordenamento jurídico, de onde resulta a primazia, seguindo a conceptualização Kelseniana, da norma coerciva como expressão jurídica do dever ser; já a nomodinâmica centra-se na análise do sistema jurídico como factor de produção normativa, assumindo as normas de atribuição de competência o lugar de destaque.

A questão nomoestática/nomodinâmica dirime-se, pois, em saber se o primacial objecto analítico é a norma na sua forma lógica proposicional de dever ser ou na norma como critério legal de atribuição de competência. Procurando responder à questão afirma o nosso autor que o "princípio estático e o princípio dinâmico estão reunidos numa e na mesma norma quando a norma fundamental pressuposta se limita, segundo o princípio dinâmico, a conferir poder a uma autoridade legisladora, e esta mesma autoridade ou uma outra por ela instituída não só estabelecem normas pelas quais delegam noutras autoridades legisladoras, mas também normas pelas quais se prescreve uma determinada conduta dos sujeitos subordinados às normas e das quais - como o particular do geral - podem ser deduzidas novas normas através de uma operação lógica"61.

Hans Kelsen parece ensinar que a questão da dicotomia nomoestática/nomodinâmica é mais aparente do que real na medida em que cada uma destas dimensões comporta uma função bem precisa na produção normativa, actividade que resulta da conjugação das duas dimensões do sistema. O princípio nomodinâmico tem, na estrutura escalonado do Direito, uma função puramente eidética de validade formal da norma produzida, a qual deve ser produzida nos termos postos pela norma de escalão superior; a norma fundamental fornece apenas o critério de validade e não o conteúdo da norma ${ }^{62}$. 0 princípio

59 Lamego, José-, "A Teoria Pura do Direito entre logicismo e voluntarismo». In: Caminhos da Filosofia do Direito Kantiana - I volume ..., pp. 137 e ss., discute a questão de saber qual o mais relevante autor que Kelsen seguiu para assumir o sistema jurídico como dinâmico, se Fritz Sander ou Adolf Julius Merkl (ambos discípulos de Kelsen).

60 Capítulo X, secção a. (o Direito como um sistema dinâmico de normas), pp. 165 a 168.

61 Kelsen, Hans - Teoria Pura do Direito ..., pp. 219 e 220.

62 Kelsen, Hans - Teoria Pura do Direito ..., pp. 219. 
nomodinâmico revela apenas a atribuição de competência ao órgão para produzir a norma e o procedimento que o mesmo órgão deve respeitar, sem abordar a dimensão material da norma.

Já o teor da norma será revelado pelo princípio nomoestático e deduzido da norma geral por uma operação mental de matriz lógica. Assim, da norma geral "devemos amar o nosso próximo" podemos deduzir as normas "não devemos fazer mal ao próximo", "não devemos, especialmente, causar-lhe a morte", "não devemos prejudicá-lo moral ou fisicamente" e "devemos ajudá-lo" quando precise de ajuda"63. Os limites materiais da norma de escalão inferior na estrutura escalonada do Direito são aferidos em razão do princípio nomoestático ${ }^{64}$.

Entre nomodinâmica e nomoestática gera-se, desta forma, uma relação de mútua dependência na produção normativa não sendo possivel a formulação de normas sem a convocação simultânea de ambos os princípios, pelo que se entende a afirmação que "O princípio estático e o princípio dinâmico estão reunidos numa e na mesma norma”65.

A suposta dificuldade em compatibilizar a nomodinâmica com a Teoria da Norma Completa ganha novos contornos à luz do que acabámos de expor, porquanto a necessidade de reunir numa mesma norma os princípios nomodinâmico e nomoestático para que o sistema possa revelar o dever ser contido numa norma dotada de coercibilidade, faz concluir que tal dificuldade não só inexiste como a nomodinâmica parece essencial à fixação do dever ser revelado pela norma completa. Mais que uma dificuldade, a recepção da nomodinâmica no edifício conceptual da Teoria Pura do Direito parece melhor adequar todo o modelo à Teoria da Norma Completa na exacta medida em que a proposição reveladora da relação de imputação jurídica (se $\mathbf{A}$ é, $\boldsymbol{B}$ deve ser) que se aplica casuisticamente não é compreensivel, rectius apreensível, sem a dimensão nomodinâmica do sistema.

A existência da norma, porque a realidade que integra não é perceptível pelos critérios do espaço e/ou do tempo (a norma é entidade com natureza de dever ser e não factual), é aferida em razão da sua validade ${ }^{66}$. A norma válida existe na ordem jurídica e a norma não válida não existe na ordem jurídica; a validade é o modo particular de existência da norma jurídica $^{67}$. A norma é valida porque inserida num sistema vertical e recebe a sua legitimi-

63 Kelsen, Hans - Teoria Pura do Direito ..., pp. 217.

64 LAMEgo, JosÉ - «Teoria da norma e teoria do sistema jurídico». In: Caminhos da Filosofia do Direito Kantiana - I volume ..., p. 85 .

65 Kelsen, HANS - Teoria Pura do Direito ..., pp. 219 (cfr. supra nota 61).

66 LAMEgo, JosÉ - «A argumentação transcendental em Kelsen». In: Caminhos da Filosofia do Direito Kantiana - I volume ..., p. 119.

67 Matos, Anditas Soares de Moura Costa- «Kelsen e a Violência: Uma Leitura Crítica das "Limitações" da Teoria Pura do Direito». In: Hans Kelsen - Teoria Jurídica e Política..., p. 256, considera que o conceito de validade é a principal estrutura operativa da Teoria Pura do Direito. 
dade, enquanto tal, de outra norma de grau superior que lhe confere validade ${ }^{68}$ e assim sucessivamente até se chegar à norma fundamental que valida todo o sistema do topo para a base; em suma, a norma é válida pela sua compatibilidade vertical. O princípio nomodinâmico traduz esta realidade da estrutura escalonada do Direito numa cadeia sucessiva de permissões de produção normativa pelo que a omissão da sua consideração levaria, de modo inapelável, à incapacidade de o sistema produzir normas dotadas de coercibilidade (a coercibilidade é, desde logo, característica da grundnorm) ${ }^{69}$; sem a dimensão nomodinâmica o sistema seria incapaz de produzir normas válidas ${ }^{70}$.

Sem a visão monodinâmica do sistema jurídico a estrutura da Teoria Pura do Direito ficaria inacabada em aspectos essenciais (a produção e a validade normativas), razão pela qual a recepção da nomodinâmica por Hans Kelsen, mais que uma dificuldade, corresponde a uma necessidade conceptual que se adequa à Teoria Escalonada do Direito e permite melhor perceber as relações normativas o que potencia o entendimento da proposição reveladora da relação de imputação jurídica como faz a Doutrina da Norma Completa.

Aceitamos, naturalmente, que a recepção da nomodinâmica no seu confronto com a Doutrina da Norma Completa torna claro "que a diferenciação hierárquica ou de níveis normativos é indissociável do reconhecimento de uma diversidade funcional entre normas e coloca no centro da análise a função normativa de atribuição de competência (Ermächtigung) e não as normas que ordenam (gebieten) ou prescrevem condutas"71. Porém, a questão é analítico-metodológica e não substantiva. Na verdade, a deslocação do primacial objecto analítico da ciência do Direito da norma que prevê a conduta obrigatória ou a permite, para a noma atribuidora de competência é, para a essência da Doutrina da Norma Completa, irrelevante uma vez que a proposição jurídica reconstruída pela ciência do Direito é constituída pelas normas autónomas e não autónomas.

Mesmo na fase inicial da construção da Doutrina da Norma Completa a nomodinâmica estava já subentendida na medida em que as normas de atribuição de competência já eram entendidas como fragmentos da proposição que resulta da reconstrução do material dado pelo legislador nas diversas normas integrantes da ordem jurídica ${ }^{72}$. A mutação da

68 Matos, Anditas Soares de Moura Costa- «A Norma Fundamental de Hans Kelsen Como Postulado Científico». In: Revista da Faculdade de Direito UFMG..., p. 49.

69 Kelsen, HANS - Teoria Pura do Direito ..., p. 56.

70 Para a norma ser valida não necessita de ser eficaz, porém Hans Kelsen não deixa de afirmar que sempre é exigível um mínimo de eficácia sob pena da norma ser revogada pelo desuso. Sobre esta questão ver, MATos, Anditas SoARes de Moura Costa- «A Norma Fundamental de Hans Kelsen Como Postulado Científico». In: Revista da Faculdade de Direito UFMG..., p. 49.

71 LAmego, JosÉ - «O Direito como Técnica Social de Motivação Indirecta de Condutas». In:A Teoria Pura do Direito de Kelsen..., p. 74.

72 Atente-se no exemplo elaborado pelo próprio Kelsen a respeito do furto e já supra mencionado (cfr. nota 47). 
matriz do objecto analítico não contende com a essência da norma completa, com efeito, a questão não é ontológica, mas sim analítica.

\section{Síntese e Considerações Finais}

A procura pela pureza metodológica e conceptual da ciência do Direito, entendida como jurisprudência analítica, levou Hans Kelsen a uma reconceptualização do seu objeto. O carácter normológico do Direito e o postulado de Hume conduziam o nosso autor à conclusão de que só as normas são susceptíveis de gerar normas e de atribuir valoração jurídica aos factos.

O objecto da ciência do Direito é, pois, a norma integrada num sistema (a ordem jurídica), o que permite uma clara cissão entre o objecto do Direito e o objecto da Sociologia (factos e não normas).

A lei de Hume levou Kelsen à constatação que as normas apenas são válidas quando integradas numa relação vertical com outras normas e recebem a sua validade na relação de conformidade com a norma de nível superior que autoriza a sua produção. Neste quadro a recepção da Teoria da Estrutura Escalonada do Direito de Adolf Julius Merkel surge como adequada para explicar a validade sistémica das normas.

Para evitar o retorno ad infinitum na validade normativa (cada norma recebe a sua validade da norma de escalão superior e assim sucessivamente), estribando-se na filosofia epistemológica neokantiana, na reconfiguração que lhe é conferida pela escola de Marburgo, com destaque para Herman Cohen, Hans Kelsen conclui pela existência de uma norma fundamental a qual determina a imposição de actos de coerção para cumprimento da primeira Constituição historicamente considerada. A grundnorm não é norma posta pelo legislatio mas pressuposta (corresponde a uma categoria logico-transcendental apriorística).

A grundnorm tem natureza coerciva e transmite esta característica a toda a ordem jurídica em termos tais que a conclusão de que uma norma não está dotada de coercibilidade importa a negação da sua juridicidade. Esta característica da coercibilidade permite a distinção entre o Direito e as demais ordens normativas sociais.

A Doutrina da Norma Completa parte da ideia da existência de normas autónomas (as que estatuem actos coercivos) e de normas não autónomas (todas as que não estatuem actos da mesma natureza), para afirmar que pertence à ciência do Direito a tarefa de, mediante critérios hermenêuticos, revelar a proposição jurídica formada pelo juízo hipotético da relação de imputação (se A é, B deve ser), cristalizando a norma individual da 
estrutura escalonada do Direito. A norma completa realiza a simbiose entre a estrutura escalonada do Direito e a sua característica da coercibilidade.

Na construção dogmática kelseniana os princípios nomodinâmico e nomestático têm funções complementares na estrutura escalonada do Direito, enquanto aquele supõe a validade formal da norma produzida (a qual deve ser produzida nos termos postos pela norma de escalão superior), este revela, através de uma operação mental de natureza lógica, a materialidade da norma.

A visão nomodinâmica é essencial à Doutrina da Norma Completa na medida em que, para além de ser necessária para a fixação do dever ser revelado na norma individual, permite aquilatar da sua validade vertical, logo da sua existência como norma jurídica. A deslocação do cerne da análise jurisprudencial da norma de comportamento para a norma de atribuição de competência - fenómeno que ocorre em razão da assunção da visão nomodinâmica - concerne ao método da ciência do Direito e não à ontologia da norma completa.

Ao lado da normatividade ideal do Direito, da norma fundamental e da estrutura escalonada do Direito, a Doutrina da Norma Completa integra o edifico conceptual da Teoria Pura do Direito e esta só é compressível pela adesão simultânea e concatenada das quatro asserções. Todas estas teses interagem entre si e reciprocamente comunicam, influenciando-se e densificando o seu conteúdo, numa tetra-relação de interdependência, em termos tais que a desconsideração de uma das teses importaria o fim ou, pelo menos, a profunda mutação das outras. A plenitude da Teoria Pura do Direito só se alcança pela simultânea aquiescência com as quatro teses.

Para aquilatar da importância da Doutrina da Norma Completa no edifício conceptual da Teoria Pura do Direito, realizemos um exercício lógico de regressão.

A desconsideração da norma completa iria colocar em causa a validade das normas integrantes do sistema por não partilharem de um elemento caracterizador da norma fundamental: a coercibilidade. Todas as normas não autónomas - de todos os escalões da estrutura desde a Constituição às normas inferiores - deixariam de receber a sua validade da norma fundamental por não reproduzirem a coercibilidade, cuja fonte é a grundnorm.

Consequentemente, as normas não autónomas não seriam juridicamente válidas, deixando de cumprir a sua função de motivação indirecta de condutas, sendo expurgadas da ordem jurídica. Entre estas estão, naturalmente, as normas de atribuição de competência que são o paradigma da norma não autónoma. Tal representaria o fim do Direito e do Estado pela incapacidade de criação de normas jurídicas.

A alternativa de considerar, ainda assim, as normas não dotadas de sanções coercivas como parte integrante do Direito importaria que se colocasse em causa a sua definição 
como ordem de coercção o que também equivaleria à "morte" do Direito e do Estado, como alertou o próprio Hans Kelsen ${ }^{73}$.

Eis a valia da Doutrina da Norma Completa, no âmbito da Teoria Pura do Direito, permitir a extensão da coercibilidade a todas as normas integrantes do sistema e, como tal, garantir a sua plena validade.

\section{BIBLIOGRAFIA}

AFONSO, Elza Maria Miranda - «Passos da Teoria de Kelsen Rumo à Construção da Teoria do Direito». In: Júlio Aguiar de Oliveira e de Alexandre Travessoni Gomes Trivisonno (Coord.). Hans Kelsen - Teoria Jurídica e Política. São Paulo: Forense Universitária, 2013, pp. 42-83.

BOBBIO, Norberto - Direito e Poder. Tradução de Nilson Moulin. São Paulo: Unesp, 2008

- Teoria do Ordenamento Jurídico. $6 .^{\mathrm{a}}$ edição. Tradução de Maria Celeste Cordeiro Leite dos Santos. Brasília: Editora UnB, 1982.

BOROWSKI, Martin- «A Doutrina da Estrutura Eascalonada do Direito de Adolf Julius Merkl e a sua Recepção em Kelsen». In: Júlio Aguiar de Oliveira e de Alexandre Travessoni Gomes Trivisonno (Coord.). Hans Kelsen - Teoria Jurídica e Política. São Paulo: Forense Universitária, 2013, pp. 129-183.

CANARIS, Claus-Wilhelm - Pensamento Sistemático e Conceito de Sistema na Ciência do Direito. $2 .^{\mathrm{a}}$ edição.

Tradução de António Menezes Cordeiro. Lisboa: Fundação Calouste Gulbenkian, 1996.

CUNHA, Paulo Ferreira da- Repensar o Direito - Um Manual de Filosofia Jurídica. Lisboa: INCM, 2013.

D’ALMEIDA, Luís Duarte - "In Canonical Form: Kelsen's Doctrine of the Complete Legal Norm». In: Luís Duarte D'Almeida, J. Gardner e L. Green (Coord.). Kelsen Revisited. New Essays on the Pure Theory of Law. , Edimburgo: Hart Publishing, 2013, pp. 259- 283.

DIMOULIS, Dimitri e LUNARDI, Soraya - «A Validade do Direito na Pespectiva Juspositivista. Reflexões em Torno de Hans Kelsen». In: Júlio Aguiar de Oliveira e de Alexandre Travessoni Gomes Trivisonno (Coord.). Hans Kelsen - Teoria Jurídica Política. São Paulo: Forense Universitária, 2013, pp. 213-231.

EHRLICH, Eugen - Fundamentos da Sociologia do Direito. $2^{\text {a }}$ Edição. Tradução de René Ernani Gertz. Lisboa: Fundação Calouste Gulbenkian, 1996.

ENGISCH, Karl - Introdução ao Pensamento Jurídico. 7. ${ }^{a}$ edição. Tradução de João Baptista Machado. Lisboa: Fundação Calouste Gulbenkian, 1996.

GREEN, Michael Steven - «Hans Kelsen and the Logic of Legal Sistems». Consultado a 10/10/2019, disponível em http://scholarship.law.wm.edu/cgi/viewcontent.cgi?article.

HART, Herbert - O Conceito de Direito. 6a Edição. Tradução de Armindo Ribeiro Mendes. Lisboa: Fundação Calouste Gulbenkian, 2011.

HARTNEY, Michael - «Introduction: The Final Form of The Pure Theory of Law». In: General Theory of Norms. Oxford: Oxford Scholarship, 1991, pp. IX-LIII.

KELSEN, Hans - Teoria Pura do Direito. $2^{\mathrm{a}}$ edição (1960). Tradução de João Baptista Machado da $7^{\mathrm{a}}$ edição. Coimbra, Almedina, 2008.

- Teoria Geral das Normas. Tradução de José Florentino Duarte. Porto Alegre: Sérgio António

Fabris Editor, 1986.

73 Kelsen, Hans - Teoria Pura do Direito ..., p. 61. 
Fontes, 2000.

LAMEGO, José - Caminhos da Filosofia do Direito Kantiana - I volume de Kant ao Neo-Kantismo. Lisboa:AAFDL, 2014. - A Teoria Pura do Direito de Kelsen. Lisboa: AAFDL, 2019.

LARENZ, Karl - Metodologia da Ciência do Direito. $3^{\text {a }}$ Edição. Tradução de José Lamego. Lisboa: Fundação Calouste Gulbenkian,1997.

MATOS, Anditas Soares de Moura Costa - «Kelsen e a Violência: Uma Leitura Crítica das "Limitações" da Teoria Pura do Direito». In: Júlio Aguiar de Oliveira e de Alexandre Travessoni Gomes Trivisonno (Coord.). Hans Kelsen - Teoria Jurídica e Política São Paulo: Forense Universitária, 2013, pp. 253-279.

- «A Norma Fundamental de Hans Kelsen Como Postulado Científico». In: Revista da Faculdade de Direito UFMG. Belo Horizonte, n. ${ }^{\circ}$ 58, janeiro/junho 2011, pp. 41-84.

MÁYNES, Eduardo Garcia - Filosofia del Derecho. 10ª edição. Cidade do México: Porrua, 1998.

NINO, Carlos Santiago - Introducción al Análisis del Derecho. $2^{\mathrm{a}}$ edição, $12^{\mathrm{a}}$ reimpressão. Buenos Aires: Editorial Astrea, 2003.

PAULSON, Stanley - «Reflexões Sobre a Periodização da Teoria do Direito de Hans Kelsen». In: Júlio Aguiar de Oliveira e de Alexandre Travessoni Gomes Trivisonno (Coord.). Hans Kelsen - Teoria Jurídica e Política. São Paulo: Forense Universitária, 2013, pp. 3-37.

PIRES, Alex Sander Xavier - Justiça na Perpectiva Kelseniana. Rio de Janeiro: Freitas Bastos Editora,2013.

RAMOS, José Joaquim Monteiro - «A Dupla Perspectiva da Norma Fundamental em Hans Kelsen». In: Politeia - Revista do Instituo Superior de Ciências Policiais e Segurança Interna. Lisboa, ano X-XI-XII, 2013, 2014, 2015, volume 1 - studia varia, pp. 213-233.

ROSS, Alf - Direito e Justiça. Tradução de Edson Bini. São Paulo: Edipro, 2000.

SILVA, Ivan de Oliveira - Filosofia do Direito. São Paulo: Editora Atlas: 2010.

SPAAK, Torben - «Kelsen and Hart on the Normativity of Law». Consultado em 24/10/2019, disponível em http:// www.scandinavianlaw.se/pdf/48-24.pdf. 